\title{
INDICAÇÃO GEOGRÁFICA NO SETOR VINÍCOLA: UMA POSSIBILIDADE NO SEMIÁRIDO PIAUIENSE
}

\author{
Liária Nunes da Silva" \\ Luiz Henrique Pimenta Quintela** \\ Alan Malacarne **** $^{*}$ \\ Robelius De-Bortoli*****
}

RESUMO: A crescente competitividade observada em diversas atividades do setor primário exige das organizações e associações de produtores capacidade de planejamento, elaboração e execução de estratégias capazes de promover o alcance dos objetivos e metas organizacionais. A partir do entendimento que esse cenário competitivo eleva a Indicação Geográfica como uma estratégia de diferenciação, esse trabalho buscou mapear as condições potenciais do setor vinícola do Semiárido Piauiense, analisando a possibilidade de certificação por Indicação Geográfica. A pesquisa de campo foi realizada em uma área de plantio de uva da variedade Benitaka para analisar as características físico-químicas do solo, além da coleta de dados dos parâmetros meteorológicos que podem interferir na qualidade das uvas, tais como temperatura e umidade relativa do ar, precipitação pluviométrica e insolação total, identificados a partir da visita à estação meteorológica convencional de São João do Piauí e complementada por informações no site do Instituto Nacional de Meteorologia (INMET). As informações obtidas revelam que a interação entre os fatores edafoclimáticos de São João do Piauí e a disponibilidade de recursos hídricos para irrigação proporcionam excelentes condições para uma produção de uvas diferenciada, apresentando potencial de certificação por Indicação Geográfica, seja na modalidade Indicação de Procedência ou Denominação de Origem.

PALAVRAS-CHAVE: Assentamento Marrecas; Estratégia; Viticultura.

Doutoranda em Ciência da Propriedade Intelectual no Programa de Pós-Graduação em Ciência da Propriedade Intelectual - PPGPI. Brasil. E-mail: : liaria.nunes@ifpi.edu.br

** $\quad$ Mestre em Ciência da Propriedade Intelectual - UFS. Brasil.

*** Doutorando em Ciência da Propriedade Intelectual no Programa de Pós-Graduação em Ciência da Pro-priedade Intelectual - PPGPI. Brasil.

**** Doutor em Ciência de la Actividad Física - UNILEON. Pós-doutorado pela Universidade da Costa Rica. Programa de Pós-Graduação em Ciência da Propriedade Intelectual - PPGPI. Brasil. 


\title{
GEOGRAPHICAL INDICATION IN THE WINE SECTOR: A POSSIBILITY IN THE PIAUIENSE SEMIARID
}

\begin{abstract}
The increasing competitiveness seen in various activities of the primary sector requires organizations and producers associations' capacity of planning, elaboration and execution of strategies capable to promote the reach of the goal and objective organizational. From the understanding that this competitive scenario raises the Geographical Indication as a strategy of differentiation, this study sought to map the potential conditions in the Piauiense semiarid winery sector, analyzing the possibility of certification by Geographical Indication. The field research was realized in a grape plantation area of variety Benitaka, to analyze the physical and chemical characteristics of the soil, as well as data collection of meteorological parameters that can affect the quality of grapes, such as temperature and relative humidity of air, rainfall and the total insolation, identified from the visit to the Conventional Meteorologic Station in São João do Piauí and supplemented by information on the website of the National Institute of Meteorology. The information obtained showed that the interaction between the edaphoclimatic factors of São João do Piauí and the availability of hydrous resources for irrigation provide excellent conditions for production of different grapes, presenting certification potential for Geographical Indication, either Indication of Origin or Denomination of Origin.
\end{abstract}

KEY WORDS: Marrecas Settlement; Strategy; Viticulture.

\section{INTRODUÇÃO}

O conhecimento acerca da Indicação Geográfica foi construído, paulatinamente, quando produtores e consumidores começaram a perceber que alguns produtos que provinham de determinadas regiões apresentavam qualidades e caraterísticas específicas, e que isso poderia ser utilizado como diferencial competitivo (VIEIRA et al., 2014).

Além de proteger a identidade territorial, a Indicação Geográfica pode ser considerada um importante instrumento de desenvolvimento territorial (PIMENTEL, 2013). No que se refere a à legislação brasileira, a Indicação Geográfica pode ser registrada como Indicação de Procedência (IP) - quando o nome geográfico de país, cidade, região ou localidade de seu território tenha se tornado conhecido como 
centro de extração, produção ou fabricação de determinado produto ou prestação de determinado serviço; ou Denominação de Origem (DO), se o nome geográfico de país, cidade, região ou localidade de seu território designam produtos ou serviços cujas qualidades ou características se devam exclusiva ou essencialmente ao meio geográfico, incluídos fatores naturais e humanos (BRASIL, 1996).

De acordo com Faria, Oliveira e Santos (2012), o moderno conceito de inovação para o agronegócio brasileiro teve início em 2002, com a IP Vale dos Vinhedos - região que abrange os municípios de Bento Gonçalves, Garibaldi e Monte Belo do Sul (RS).

De fato, o Brasil vem produzindo vinho desde o começo de sua colonização, sendo os portugueses - especialmente Martim Afonso de Souza - os precursores do cultivo de videiras no país, ainda em 1532 na Capitania de São Vicente (PROTAS; CAMARGO; MELO, 2014). A partir de então, houve outras tentativas, mas foi em 1626, com a chegada dos jesuítas à região das Missões que a vitivinicultura brasileira, sobretudo a da região Sul do país, começou a despontar. No entanto, foi com a chegada dos imigrantes italianos em 1875 , que trouxeram o conhecimento técnico de elaboração de vinhos e a cultura do seu consumo, que a produção nacional teve a qualidade elevada e ganhou expressividade e importância econômica (IBRAVIN, 2016).

Somente em 1960, quatro séculos após a introdução das primeiras videiras no Brasil, é que a viticultura tropical começou a ser desenvolvida na região do Vale do Submédio São Francisco, localizado no semiárido brasileiro, com a implantação de vinhedos voltados para a produção e comercialização de uvas de mesa; atualmente a principal região vitícola tropical do país (PROTAS; CAMARGO; MELO, 2014).

Além do Vale do Submédio São Francisco outras áreas do semiárido do Nordeste brasileiro destacam-se na produção de uvas sob sistemas de irrigação, a exemplo de São João do Piauí (PI); a viticultura no município iniciou em 2004, por intermédio das ações de Hildo Diniz, superintendente à época da Companhia de Desenvolvimento dos Vales do São Francisco e Parnaíba (CODEVASF), que articulou a implantação de um projeto piloto de irrigação no Assentamento Marrecas, objetivando desenvolver o potencial produtivo da fruticultura local, sobretudo a partir do cultivo de uvas europeias (Vitis Vinífera L.), especialmente das variedades Itália melhorada, Benitaka e Brasil. 
Diante do progresso do setor vinícola e da urgência de ressaltar a originalidade e qualidade das uvas e vinhos brasileiros, bem como de protegê-los contra falsificações, o Brasil vem fazendo uso dos mecanismos da propriedade industrial, especificamente da Indicação Geográfica, como ferramenta de valorização da produção nacional, uma vez que certifica a originalidade dos produtos, protege a tradição local e promove o desenvolvimento econômico regional (BRANDÃO, 2014).

Os pedidos de Indicação Geográfica no Brasil vêm aumentando nos últimos cincos anos, apesar das discussões a respeito do assunto serem recentes no país, principalmente se comparado a países da Europa e da Ásia (MAIORKI; DALLABRIDA, 2015). Segundo Mello et al. (2014), houve avanços significativos no desenvolvimento de Indicações Geográficas para vinhos finos nos últimos anos e que elas estão se estabelecendo como um elemento novo no setor vitivinícola do país, reorganizando a produção e valorizando produtos e territórios junto ao mercado nacional e internacional.

De acordo com Porter (2009) é por meio das estratégias que as organizações oferecem valor superior a seus clientes. Além do que, as organizações criam vantagens competitivas quando percebem novas maneiras de competir em um segmento industrial e se dispõem a criar estratégias diferenciadas para superar os concorrentes. Dessa forma, a Indicação Geográfica surge como uma estratégia competitiva de diferenciação capaz de reconhecer a singularidade dos produtos/serviços e garantir o uso exclusivo pela organização detentora da sua tutela.

Tendo em vista os argumentos acima apresentados, objetivou-se com este trabalho mapear as condições potenciais do setor vinícola do Semiárido Piauiense, analisando a possibilidade de certificação por Indicação Geográfica.

\section{MATERIAL E MÉTODOS}

A escolha da área de abrangência da pesquisa - Assentamento Marrecas, localizado em São João do Piauí (PI) (latitude 08²1'29” S, longitude $42^{\circ} 14$ '48” W e altitude $222 \mathrm{~m}$ ) - justifica-se pelo fato de o município se destacar no Estado do Piauí como produtor de vinhas. 
Com o objetivo de conhecer as características físico-químicas do solo da plantação de uvas realizou-se a coleta de solo em uma área correspondente a 1 hectare, situada a $08^{\circ} 14.101^{\prime}$ S e $042^{\circ} 27.946$ ' W, onde é cultivada a variedade Benitaka, conduzida por um sistema do tipo latada, com varas amarradas horizontalmente aos fios de sustentação dos vinhedos. As videiras estão em fileiras, com distância aproximada de 2,5 metros, uma da outra, e 1,5 m de distância entre as plantas.

Foram coletadas 20 amostras simples, de forma aleatória nas linhas do plantio, a profundidade de 0-20 cm cada, considerando os critérios descritos para a cultura (MELO; SCHNEIDER, 2007; CANTARUTTI; ALVAREZ; RIBEIRO, 1999; NOVAIS et al., 2007). Na realização do procedimento utilizou-se enxadas para a perfuração do solo e sacos plásticos para acondicionar a amostra.

Na sequência, as amostras simples foram colocadas no mesmo recipiente e misturadas, obtendo assim, a amostra composta. Para Novais et al. (2007), é importante que as amostras simples sejam misturadas, de maneira que se consiga uma amostra composta homogênea, retirando na sequência uma subamostra, um volume em torno de $300 \mathrm{~cm}^{3}$. A amostra composta foi acondicionada em saco plástico e entregue para análise no dia 25 de abril de 2016 ao Laboratório de Solo da Embrapa Semiárido e registrada com o número de protocolo 16.166.612.

Posteriormente, foi realizada uma visita à estação meteorológica convencional de São João do Piauí, com o objetivo de coletar dados acerca dos parâmetros meteorológicos - temperatura e umidade relativa do ar, precipitação pluviométrica e radiação solar - que podem interferir na qualidade das vinhas. Além disso, efetivou-se uma busca no site do INMET para localizar esses dados no período entre janeiro de 2015 a janeiro de 2016. A busca foi feita no site inserindo o parâmetro meteorológico a ser pesquisado e o período de abrangência.

\section{RESULTADOS E DISCUSSÃO}

\subsection{FATORES EDÁFICOS}

Para a caracterização física da área de cultivo de videiras no Assentamento Marrecas foram definidos os valores de areia, silte e argila, posto que a textura 
do solo refere-se à proporção relativa das frações granulométricas desses minerais (SANTOS et al., 2015).

Os resultados apresentados para as frações minerais da areia $(21,4 \mathrm{~g} / \mathrm{kg})$, silte $(46,4 \mathrm{~g} / \mathrm{kg})$ e argila $(32,2 \mathrm{~g} / \mathrm{kg})$ indicaram que a classe textural do solo analisado é Franco-argilosa, corroborando os ensinamentos de Lepsch (2011) quando afirma que solos com essas características podem assim serem classificados.

Segundo Gliessman (2015), em aspectos gerais, um solo Franco-argiloso é o mais indicado em ambientes secos, devido à ação controladora da argila nas propriedades relevantes para as culturas, como a troca de íons entre as partículas e a água do solo. As partículas com cargas elétricas, presentes na argila, lhes fornecem capacidade de atrair íons nutrientes disponíveis para as plantas e, em virtude dessa habilidade de atração e retenção, as perdas de nutrientes vegetais por lixiviação são menores do que em solos arenosos (TROEH; THOMPSON, 2007).

Além do que, solos de textura franca apresentam potencial para o desenvolvimento radicular das plantas e capacidade de reter umidade, aspectos relevantes para o seu crescimento (MELO, 2014). Por isso, é importante considerar-se a aptidão edáfica para a viticultura. Isso porque constatou-se que a videira apresenta adaptabilidade a vários tipos de solos; porém, desenvolve-se melhor naqueles com textura franca (MELO, 2005).

Assim como as características físicas do solo (profundidade, estrutura e textura) as características químicas também influenciam nas respostas de produção das videiras, sendo que a reação do solo - pH - e a disponibilidade de nutrientes exercem maior influência (MELO, 2014). Observaram-se os seguintes valores para os atributos químicos do solo da região: $\mathrm{pH}$ em $\mathrm{H}_{2} \mathrm{O}=6,5$, fósforo $(\mathrm{P})=10,86 \mathrm{mg}$ / $\mathrm{dm}^{3}$, potássio $(\mathrm{K})=78,2 \mathrm{mg} / \mathrm{dm}^{3}$ e saturação por bases $=95,7 \%$.

No tocante ao $\mathrm{pH}$ - $(6,5)$ - observou-se que o solo está no limite, entre levemente ácido e muito levemente ácido, uma vez que qualquer pH abaixo de 7,0 é ácido e, acima, é alcalino, sendo considerado neutro quando atinge o valor 7,0.

Porém, é pertinente salientar que o $\mathrm{pH}$ do solo depende de uma variedade de fatores, tais como: estação do ano, práticas culturais, horizontes de solo amostrado, conteúdo da água na época da amostragem, bem como o método pelo qual o pH é determinado; sendo assim, passível de correções a partir de aplicações 
de calcário e fertilizantes químicos ou orgânicos. A matéria orgânica, por exemplo, pode aumentar a capacidade de troca de cátions (CTC) - capacidade que o solo tem de armazenar nutrientes para as culturas - além de suprir as necessidades de nitrogênio, fósforo e enxofre (TROEH; THOMPSON, 2007; PRETERE; CUNHA, 2010).

A videira é pouco exigente em nutrientes para se desenvolver, mas dentre os considerados essenciais, estão o fósforo (P) e o potássio (K). O fósforo (P) participa na atividade fotossintética da planta e é essencial na transformação do amido em açúcar. A escassez desse elemento reduz o desenvolvimento das folhas, além de provocar, prematuramente, a sua queda e a maturação dos frutos. Já o potássio (K) desempenha um papel importante na qualidade da uva, agindo sobre a produção de carboidratos, na cor e brilho do fruto. A sua insuficiência retarda a maturação dos frutos e favorece a produção de cachos pequenos, frutos duros, verdes e ácidos (SIMÃO, 1998; FARIA; SILVA, 2004).

Os resultados da análise química demonstram que os teores de fósforo (P) $\left(10,86 \mathrm{mg} / \mathrm{dm}^{3}\right)$ e potássio $(\mathrm{K})\left(78,2 \mathrm{mg} / \mathrm{dm}^{3}\right)$ estão na faixa média em relação à fertilidade do solo, haja vista que solos com teores de argila em torno de 21 a $40 \%$ - o solo amostrado apresenta 32,2\% - manifestam média CTC, média concentração de fósforo (P) e de potássio (K) (SBCS, 2004).

Os resultados apurados nas análises evidenciam que o cultivo de videiras em São João do Piauí ocorre em uma área que não apresenta limitações a seu desenvolvimento potencial. Após a correção da acidez, a partir da aplicação de calcário, práticas utilizadas pelos produtores da região, o solo apresentou $\mathrm{pH}$ dentro dos limites considerados ótimos, nutrientes na faixa média em relação à fertilidade do solo e $95,7 \%$ de saturação por base (V\%), índice que revela as condições gerais de fertilidade do solo, podendo ser utilizado, inclusive, para classificá-los como eutróficos (férteis) ou distróficos (pouco férteis). Portanto, o solo da região é considerado fértil, pois segundo Ronquim (2010) o solo que apresenta um índice de saturação por base igual ou superior a 50\% é classificado como eutrófico (fértil).

\subsection{FATORES CLIMÁTICOS}

A aptidão de São João do Piauí para a viticultura foi analisada a partir da sua semelhança climática com o munícipio de Petrolina (PE), apontada por Hildo 
Diniz - responsável pela implantação da viticultura sob sistema de irrigação no município. Segundo Andrade Júnior et al. (2004b), essa região, tipicamente semiárida, se caracteriza pelas baixas precipitação pluviométrica e umidade relativa do ar, além de altas temperatura do ar e radiação solar, produzindo condições que minimizam as ocorrências de doenças, pois quando cultivada em áreas de umidade do ar elevada e de temperaturas brandas, a videira fica mais suscetível a desenvolver doenças fúngicas (GARRIDO; SONÊGO, 2003).

A Figura 1 demonstra o comportamento das temperaturas mínima, média e máxima em São João do Piauí no período entre janeiro/2015 a janeiro/2016.

\section{Temperatura mínima, média e máxima}

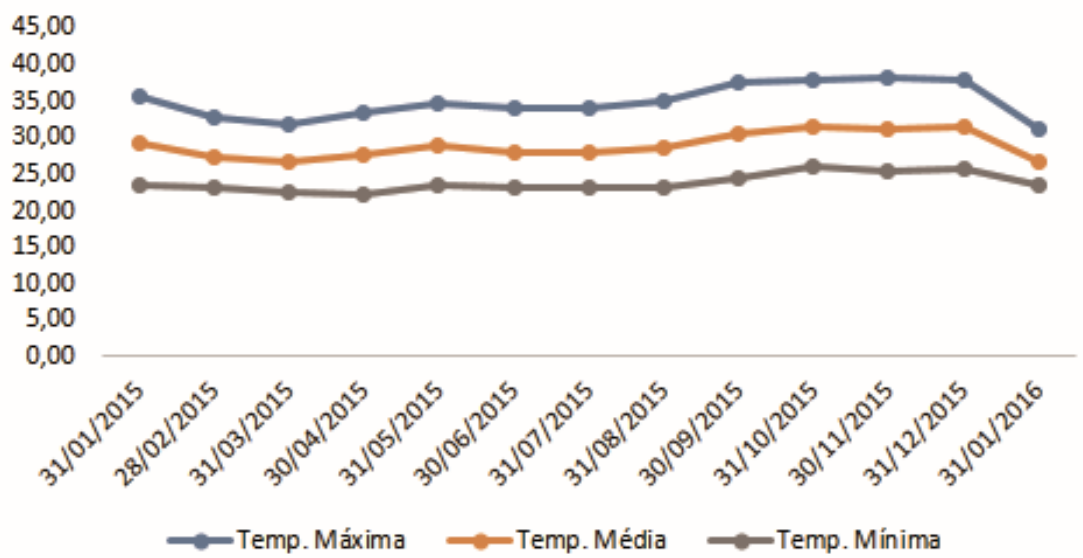

Figura 1. Temperaturas mínima, média e máxima

Apesar da elevação da temperatura nos meses que compõem o trimestre setembro-novembro, é possível perceber um comportamento, relativamente estável durante o ano, especialmente em relação à temperatura máxima que se apresenta, praticamente igual no período. Esse comportamento da temperatura proporciona uma produção padronizada, não apresentando grandes variações no sabor das vinhas produzidas ao longo do ano.

Manica e Pommer (2006) explicam que, apesar de a produtividade da videira ser influenciada por temperaturas elevadas, no início da dormência são exigidas temperaturas inferiores a $20{ }^{\circ} \mathrm{C}$. Em regiões de climas tropicais, onde essas 
temperaturas não são facilmente alcançadas, o período de dormência é atingido por meio do manejo de água durante o período de repouso (TEIXEIRA et al., 2012).

No cultivo de videiras no Vale do Submédio São Francisco, onde o repouso vegetativo é obtido pela suspensão do fornecimento de água, a produção de uva ocorre em qualquer época do ano (POMMER, 2003), e em São João do Piauí, que no estágio de repouso vegetativo a irrigação é reduzida a uma quantidade mínima, garantindo que a planta mantenha sua atividade fotossintética, assim como o escalonamento da produção ao longo do ano.

As informações obtidas no período - janeiro/2015 a janeiro/2016 - demonstram que São João do Piauí apresenta temperatura média ideal para a produção de uvas de mesa de aproximadamente $29^{\circ} \mathrm{C}$. Segundo Teixeira et al. (2012) as temperaturas em torno de 20 e $30^{\circ} \mathrm{C}$ são as mais indicadas para a viticultura, uma vez que favorecem a homogeneidade dos processos de coloração, concentração de sólidos solúveis e da acidez do fruto durante as diversas safras.

Observando os números relativos à precipitação pluviométrica do município de São João do Piauí no período estudado - Figura 2 - e entendendo que tal comportamento é compatível e esperado para uma região localizada no Semiárido Piauiense, a irregularidade das chuvas é um fenômeno que se destaca, mesmo sendo recorrente e conhecido.

\section{Precipitação Total}

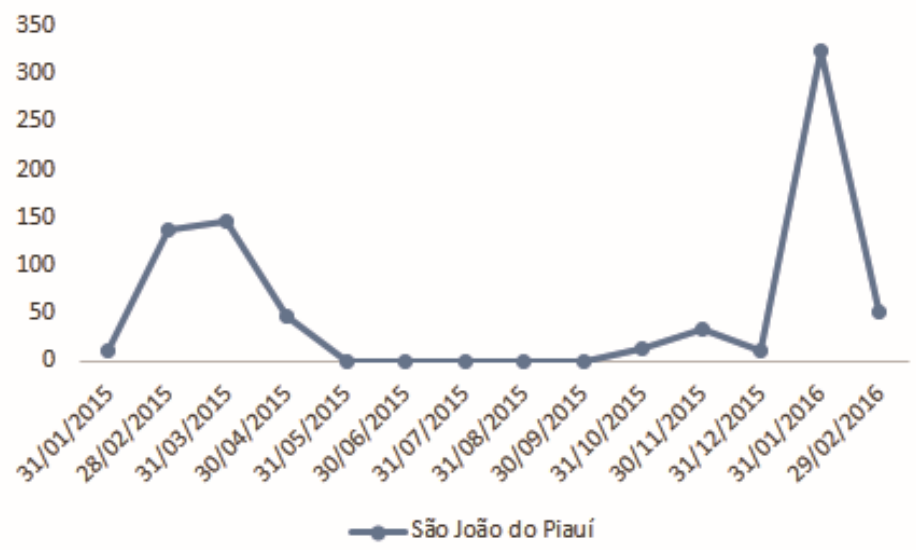

Figura 2. Precipitação Pluviométrica 
Ainda que o volume anual de precipitação pluviométrica tenha atingido aproximadamente $772 \mathrm{~mm}$ no ano estudado, é possível perceber a significativa heterogeneidade da ocorrência de chuvas no município, a exemplo dos períodos outono-inverno, em que praticamente não há registros de chuvas, e primavera-verão, época de maiores volumes de chuva na região, registrando, inclusive, o maior volume de precipitação em janeiro, 323,20 mm.

A escassez de chuva observada no período de maio a setembro de 2015 não se configura como um fator limitante para a viticultura no município, uma vez que a necessidade de água da cultura é suprida por meio de irrigação. Segundo Sousa et al. (2011), o emprego da irrigação na viticultura, especialmente em variedades de mesa, vem sendo utilizado em várias regiões áridas e semiáridas do mundo, sendo essa a principal fonte de água para a cultura, enquanto em outras regiões ela pode ser adotada de forma complementar.

Efetivamente, a viticultura de São João do Piauí não apresenta desvantagens em relação à viticultura de regiões que registram grandes volumes de precipitação pluviométrica durante o ano. Segundo Teixeira (2004), a videira possui um sistema radicular capaz de atingir grandes profundidades, permitindo a planta tolerar períodos de baixa pluviosidade. Tais características, quando associadas a sistemas de irrigação, possibilita ao produtor controlar a quantidade de água aplicada na cultura, visto que a sua demanda hídrica altera em razão dos diferentes estágios do ciclo vegetativo.

Verificando as Figuras 1 e 2, temperaturas mínima, média e máxima e precipitação pluviométrica, respectivamente, duas informações merecem destaque: a primeira é que a menor temperatura registrada entre janeiro/2015 e janeiro/2016 foi de $22,17^{\circ} \mathrm{C}$, no mês de abril, e a maior foi de $38,20{ }^{\circ} \mathrm{C}$, no mês de novembro; e a segunda é a vantagem competitiva proporcionada pelo conjunto "temperaturas elevadas e baixo índice pluviométrico", condições climáticas que proporcionam vinhas com uma concentração maior de açúcar em detrimento do ácido málico (TEIXEIRA; AZEVEDO, 1996; TEIXEIRA; MOURA; ANGELOTTI, 2010).

A insolação é considerada um fator valoroso nos processos de evapotranspiração das culturas, de fotoenergia e de fotoestímulos, bem como nas etapas de desenvolvimento da baga e na definição da composição química da uva (TEIXEIRA et al., 2012; TONIETTO; MANDELLI, 2003). Analisando a Figura 3 - insolação total - percebe-se que São João do Piauí possui um importante aliado na produção de vinhas, pois registrou grande uniformidade na ocorrência de radiação solar no pe- 
ríodo de janeiro/2015 a janeiro/2016, sobretudo entre os meses de julho a dezembro de 2015.

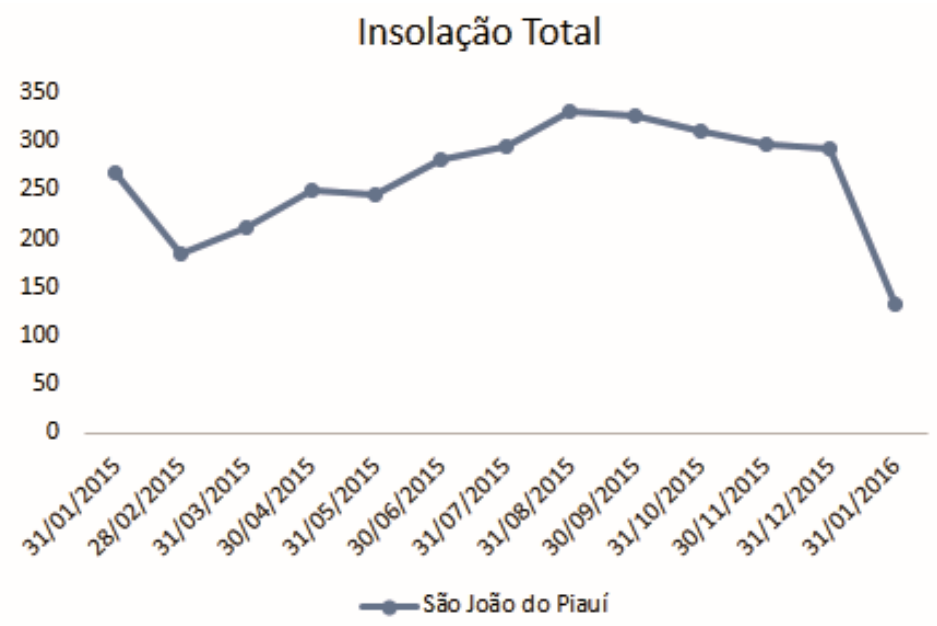

Figura 3. Insolação Total

Ainda que haja redução da incidência de insolação entre os primeiros meses de 2015, nota-se que há uma tendência de elevação desse parâmetro meteorológico durante o ano. Esse comportamento é interessante para a viticultura da região, uma vez que a videira é exigente em radiação solar; o que favorece uma produção de frutos com maior concentração de açúcares (TONIETTO; MANDELLI, 2003; TEIXEIRA; MOURA; ANGELOTTI, 2010).

Comparando as figuras de precipitação pluviométrica e de insolação total de São João do Piauí - Figuras 2 e 3 -, observa-se que há uma relação inversamente proporcional das variáveis na região, ou seja: quando a precipitação atingiu os seus maiores volumes no período primavera-verão, a insolação registrada foi a de menor incidência.

Outra variável associada à qualidade das vinhas é a umidade relativa do ar. Quando a umidade se apresenta com valores mais elevados, ela proporciona o desenvolvimento de ramos mais vigorosos, acelera a emissão das folhas e favorece uma maior longevidade, contudo, associada a temperaturas elevadas, ela aumenta a incidência de doenças fúngicas e bacterianas (TEIXEIRA; MOURA; ANGELOTTI, 
2010). A maioria das regiões onde a videira europeia é cultivada com fins comerciais apresenta índice de umidade variando entre -60, máxima aptidão climática e poucos problemas fitossanitários, e 60, acima desse valor já não é possível o cultivo comercial (TEIXEIRA et al., 2002).

De acordo com o INMET (2009), corroborado por Andrade Júnior et al. (2010), as menores faixas de umidade relativa do ar no Piauí (60\% a 65\%) predominam na região Sudeste, onde se localiza São João do Piauí. Por conta dessa localização, o município apresenta índices de umidade, segundo a classificação de Thornthwaite e Mather (1995), inferiores a -33,3, demonstrando um elevado potencial climático para a produção de uva de mesa e vinhos doces (ANDRADE JÚNIOR et al., 2009), vale acrescentar, índice muito próximo daqueles que favoreceram a produção da videira europeia em Argel, Argélia -32,8 - e em Varna, Bulgária - 33,6 (TEIXEIRA et al., 2002).

O comportamento da umidade relativa do ar em São João do Piauí no período entre janeiro/2015 a janeiro/2016 - assim como a temperatura, a precipitação pluviométrica e a insolação - se apresentou compatível com o esperado para municípios da região Semiárida do Nordeste Brasileiro, caracterizados por baixos índices de precipitação e temperaturas elevadas.

\section{Umidade Relativa Média}

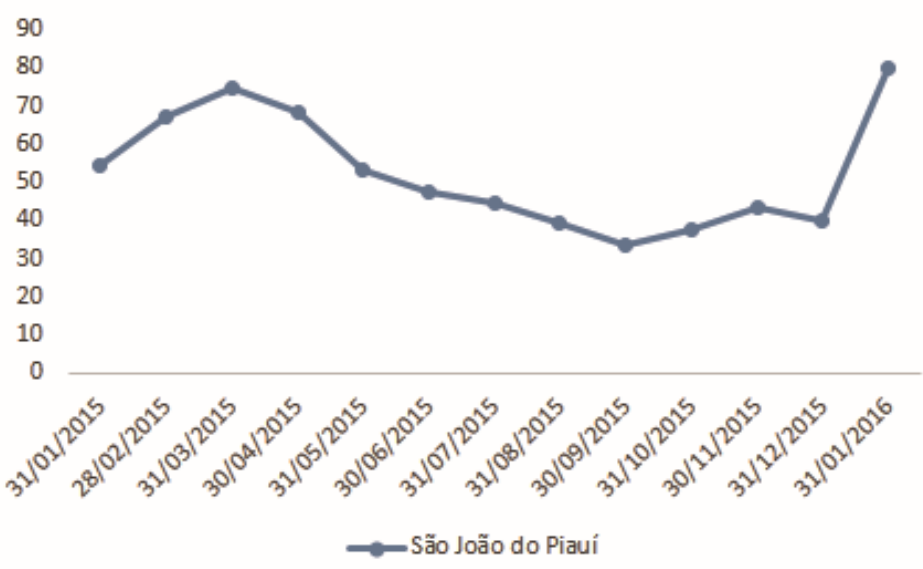

Figura 4. Umidade Relativa do ar Média 
Verifica-se que as menores taxas de umidade relativa do ar - Figura 4 - foram registradas nos meses de estiagem, especialmente no trimestre de setembro-outubro-novembro, quando são apresentadas as temperaturas mais elevadas. Já no período que compreende os meses de janeiro a abril, em que a umidade relativa do ar está mais alta, apresenta temperaturas mais brandas e maiores volumes de precipitação pluviométrica - ver Figuras 1, 2 e 4.

A viticultura em regiões de climas mais áridos é exposta a menores índices de umidade relativa do ar, ao contrário das regiões de climas mais úmidos, como o Sul do Brasil, que apresentam taxas de umidade mais elevadas (TONIETTO; MANDELLI, 2003).

Todavia, considerando a caracterização climática da região Semiárida do Nordeste brasileiro, marcado por elevadas temperaturas, é providencial para o cultivo de videiras que a umidade relativa do ar se apresente em níveis mais baixos, uma vez que valores mais elevados, apesar de estimular o desenvolvimento vegetativo da videira, quando associados a altas temperaturas favorecem o surgimento de doenças fúngicas (TEIXEIRA, 2004; TEIXEIRA; MOURA; ANGELOTTI, 2010).

Em estudos voltados para delimitar a aptidão agroclimática para o cultivo de videira sob sistemas de irrigação no Nordeste do Brasil, Teixeira et al. (2012) concluíram que as áreas qualificadas como adequadas para a viticultura exibiram maiores disponibilidades térmicas, baixos níveis de umidade do ar e precipitação pluviométrica.

Dessa forma, pode-se verificar que a região de São João do Piauí apresenta condições similares, que consequentemente contribuem para uma menor incidência de doenças e dos problemas provocados pelo excesso de chuvas, bem como para a elevação da produção e qualidade dos frutos. Esses fatores foram utilizados na constituição da justificativa de solicitação de Indicação de Procedência para uvas de mesa e mangas produzidos no Vale do Submédio Francisco, concedida pelo Instituto Nacional de Propriedade Industrial (INPI) em 2009 (LIMA, 2009).

Portanto, assim como os produtores do Vale do Submédio São Francisco, os produtores do Assentamento Marrecas podem utilizar essas especificidades agrometeorológicas da região para solicitar e justificar, junto ao INPI, o selo de Indicação Geográfica para a uva produzida no local, uma estratégia de negócio capaz de asse- 
gurar a origem e o valor do produto, assim como a penetração em outros mercados, a exemplo dos demandantes por produtos com certificação.

\section{CONSIDERAÇÕES FINAIS}

Efetivamente, a interação entre os fatores climáticos, os solos profundos da região e a disponibilidade de recursos hídricos para a irrigação proporcionam vantagens competitivas à viticultura do Semiárido Piauiense.

A produção vitícola do Assentamento Marrecas apresenta potencial para receber o signo distintivo de Indicação Geográfica, tanto na modalidade Indicação de Procedência, quanto Denominação de Origem.

A Indicação Geográfica para a produção de uva do Assentamento Marrecas se configura como uma ferramenta estratégica eficaz para impulsionar, diretamente, a atividade vinícola local e, indiretamente, outros segmentos da economia, tais como o turismo, especialmente o enoturismo e o turismo de base comunitária, proporcionando avanços expressivos no desenvolvimento econômico da comunidade e da região; além de fortalecer a organização dos produtores.

Do mesmo modo que as Indicações Geográficas do Vale do Submédio São Francisco e do Vale dos Vinhedos, a Indicação Geográfica do Assentamento Marrecas provocará uma série de impactos positivos diretos na área demarcada, como: garantia da origem e do valor do produto; maior facilidade de penetração no mercado; melhoria na imagem do produto, na visão do consumidor; estímulo a investimentos na cadeia produtiva; condições favoráveis para a permanência dos produtores na zona rural; satisfação do produtor diante da valorização do seu produto; maiores retornos financeiros; e preservação do saber-fazer, da tradição e cultura.

\section{REFERÊNCIAS}

ANDRADE JÚNIOR, A. S.; BASTOS, E. A.; SILVA, C. O.; GOMES, A. A. N.; FIGUEREDO JÚNIOR, L. G. M. Atlas climatológico do Estado do Piauí. Teresina: Embrapa Meio-Norte, 2004b. 151 p. (Embrapa Meio-Norte. Documentos, 101). 
ANDRADE JÚNIOR, A. S.; BASTOS, E. A.; SILVA, C. O. Zoneamento de aptidão climática para a videira europeia no Estado do Piauí. Teresina: Embrapa Meio-Norte, 2009.

ANDRADE JÚNIOR, A. S.; TONIETTO, J.; BASTOS, E. A.; CONCEIÇÃO, M. A. F. Potencial climático da regiáo semiárido do Piauí para a produção de uvas destinadas à elaboração de vinhos finos. Teresina: Embrapa Meio-Norte, 2010.

BRANDÃO, C. D. Fatores intervenientes na implementação de ações estratégicas para a promoção do selo de Indicação Geográfica das panelas de barro de Goiabeiras. 2014. 143f. Dissertação (Mestrado em Administração) - Universidade Federal do Espírito Santo, Vitória, 2014.

BRASIL. Lei 9.279, de 14 de maio de 1996. Regula direitos e obrigações relativos à propriedade industrial. Disponível em: < http://www.planalto.gov.br/ccivil_03/leis/ L9279.htm > . Acesso em: 16 fev. 2016.

CANTARUTTI, R. B.; ALVAREZ V, V. H.; RIBEIRO, A. C. Amostragem do solo. In: RIBEIRO, A. A.; GUIMARÃES, P. T. G.; ALVAREZ V, V. H. Recomendações para o uso de corretivos e fertilizantes em Minas Gerais. Viçosa: UFV, 1999. p. 21-26.

FARIA, C. M. B.; SILVA, D. J. Nutrição, calagem e adubação: nutrientes essenciais e sintomas de deficiência; amostragem e análise do solo; amostragem e análise da planta; calagem; adubação. In: LEÃO, P. C. S. Cultivo da videira. Embrapa Semiárido, 2004, p. 14-18. Disponível em: < https://ainfo.cnptia.embrapa.br/digital/bitstream/item/112196/1/Cultivo-da-videira-32070.pdf > . Acesso em: 04 jan. 2016.

FARIA, L. E.; OLIVEIRA, R. S.; SANTOS, N. Propriedade industrial - Indicações geográficas: a origem do produto com diferencial de qualidade e diversidade para inovação no agronegócio brasileiro. In: PLAZA, C. M. C. Á.; DEL NERO, P. A.; TARREGA, M. C. V. B.; SANTOS, N.; FONTES, A. R. C. Propriedade intelectual na agricultura. Belo Horizonte: Fórum, 2012. p. 289-309.

GARRIDO, L. R.; SONÊGO, O. R. Uvas Viníferas para Processamento em Regióes de Clima Temperado. 4. ed. Embrapa Uva e Vinho, Sistema de Produção, 2003. Disponível em: < https://sistemasdeproducao.cnptia.embrapa.br/FontesHTML/Uva/ UvasViniferasRegioesClimaTemperado/doenca.htm> . Acesso em: 04 jan. 2016.

GLIESSMAN, S. R. Agroecologia: processos ecológicos em agricultura sustentável. 
4. ed. Reimp. Porto Alegre: Ed. da UFRGS, 2015.

INSTITUTO BRASILEIRO DO VINHO - IBRAVIN. História do vinho no Brasil. Disponível em: < http://www.ibravin.org.br/Historia-do-Vinho-no-Brasil > . Acesso em: 12 jun. 2016.

INSTITUTO NACIONAL DE METEOROLOGIA [INMET]. Normais climatológicas do Brasil 1961-1990: insolação total (horas). Disponível em: <http://www.inmet. gov.br/portal/index.php?r=clima/normaisClimatologicas $>$. Acesso em: 19 mar. 2016. Brasília: INMET, 2009.

LEPSCH, I. F. 19 lições de pedologia. São Paulo: Oficina de Textos, 2011.

LIMA, M. A. C. Subsídios técnicos para a indicação geográfica de procedência do Vale do Submédio São Francisco. Petrolina: Embrapa Semi-Árido, 2009. Disponível em: <http://www.cpatsa.embrapa.br:8080/public_eletronica/downloads/ SDC222.pdf > . Acesso em: 25 ago. 2017.

MAIORKI, G. J.; DALLABRIDA, V. R. A indicação geográfica de produtos: um estudo sobre sua contribuição econômica no desenvolvimento territorial. Interações, Campo Grande, v. 16, n. 1, p. 13-25, 2015.

MANICA, I.; POMMER, C. V. Uva: do plantio a produção, pós-colheita e mercado. Porto Alegre: Cinco Continentes, 2006.

MELO, G. W. Uvas sem sementes: Cultivares BRS Morena, BRS Clara e BRS Linda preparo do solo e adubação. Sistemas de produção, 8. Embrapa Uva e Vinho, 2005. Disponível em: < https://sistemasdeproducao.cnptia.embrapa.br/FontesHTML/Uva/ UvasSemSementes/adubacao.htm>. Acesso em: 28 jun. 2016.

MELO, G. W. B.; SCHNEIDER, E. P. Solos e adubação. In: NACHTIGAL, J. C.; SCHNEIDER, E. P. Recomendações para produção de videiras em sistemas de base ecológica. Bento Gonçalves: Embrapa Uva e Vinho, 2007, p. 23-28. Disponível em: $<$ http://www.cnpuv.embrapa.br/publica/documentos/doc065.pdf > . Acesso em: 02 maio 2016.

MELLO, L. M. R.; ZACKIEWICZ, M.; BEZERRA, L. M. C.; TONIETTO, J.; BEAULIEU, C. M. G.; CAETANO, S. F. Metodologia de avaliação de impactos econômicos, sociais e ambientais para indicações geográficas: o caso do Vale dos Vinhedos. 
Bento Gonçalves: Embrapa Uva e Vinho, 2014. Disponível em: < http://ainfo.cnptia. embrapa.br/digital/bitstream/item/114801/1/doc91.pdf > . Acesso em: 24 fev. 2016.

MELO, G. W. Adubação e manejo do solo para a cultura da videira. Bento Gonçalves: Embrapa Uva e Vinho, 2014. Disponível em: < http://www.cnpuv.embrapa. br/publica/sprod/viticultura/adubvid.html > . Acesso em: 10 jun. 2016.

NOVAIS, R. F.; ALVAREZ, V. H.; BARROS, N. F.; FONTES, R. L. F.; CANTARUTTI, R. B.; NEVES, J. C. L. Fertilidade do solo. Minas Gerais: Sociedade Brasileira de Ciência do solo, 2007. 1017 p.

PIMENTEL, L. O. Os desafios dos aspectos legais na prática de estruturação das Indicações Geográficas. In: DALLABRIDA, V. R. Território, identidade territorial e desenvolvimento regional: reflexões sobre indicação geográfica e novas possibilidades de desenvolvimento com base em ativos com especificidades territorial. São Paulo: LiberArs, 2013. p. 135-143.

POMMER, C. V. Uva: tecnologia de produção, pós-colheita, mercado. Porto Alegre: Cinco Continentes, 2003.

PORTER, M. E. Competição [tradução Afonso Celso da Cunha Serra]. ed. rev. e ampl. Rio de Janeiro: Elsevier, 2009.

PRETERE, V. G.; CUNHA, T. J. F. Manejo e conservação do solo: características dos solos cultivados com videira no Submédio do Vale do São Francisco. Sistemas de produção, $1^{\mathrm{a}}$ e $2^{\mathrm{a}}$ ed. Embrapa Semiárido, 2010. Disponível em: https:// sistemasdeproducao.cnptia.embrapa.br/FontesHTML/Uva/CultivodaVideira_2ed/ manejo.html. Acesso em: 18 jun. 2016.

PROTAS, J. F. S.; CAMARGO, U. A.; MELO, L. M. R. A vitivinicultura brasileira: realidade e perspectivas. Bento Gonçalves: Embrapa Uva e Vinho, 2014. Disponível em: <http://www.cnpuv.embrapa.br/publica/artigos/vitivinicultura/>. Acesso em: 12 jun. 2016.

RONQUIM, C. C. Conceitos de fertilidade do solo e manejo adequado para as regiões tropicais. Campinas: Embrapa Monitoramento por Satélite, 2010. Disponível em: http://ainfo.cnptia.embrapa.br/digital/bitstream/item/31004/1/BPD-8.pdf. Acesso em: 15 jun. 2016. 
SANTOS, R. D.; SANTOS, H. G.; KER, J. C.; ANJOS, L. H. C.; SHIMIZU, S. H. Manual de descrição e coleta de solo no campo. 7. ed. rev. ampl. Viçosa: Sociedade Brasileira de Ciência do Solo, 2015.

SIMÃO, S. Tratado de fruticultura. Piracicaba: FEALQ, 1998.

SOCIEDADE BRASILEIRA DE CIÊNCIA DO SOLO - SBCS. Manual de adubação e calagem: Estados do Rio Grande do Sul e Santa Catarina. 10ª ed. Porto Alegre: Comissão de Química e Fertilidade do Solo, 2004. Disponível em: < http://www.sbcs-nrs.org.br/docs/manual_de_adubacao_2004_versao_internet.pdf $>$. Acesso em: 15 jun. 2016.

SOUSA, V. F.; MAROUELLI, W. A.; COELHO, E. F.; PINTO, J. M.; FILHO, M. A. C. Irrigação e fertirrigação em fruteiras e hortaliças. Brasília: Embrapa Informação Tecnológica, 2011.

TEIXEIRA, A. H. C.; AZEVEDO, P. V. Zoneamento agroclimático para a videira européia no Estado de Pernambuco, Brasil. Revista Brasileira de Agrometeorologia, Santa Maria, v. 4, n. 1, p. 137-141, 1996.

TEIXEIRA, A. H. C.; SOUZA, R. A.; RIBEIRO, P. H. B.; REIS, V. C. S.; SANTOS, M. G. L. Aptidão agroclimática da cultura da videira no Estado da Bahia, Brasil. Campina Grande: Revista Brasileira de Engenharia Agrícola e Ambiental, v. 6, n. 1, p. 107-111, 2002. Disponível em: < http://www.scielo.br/scielo.php?script=sci_arttext\&pid=S1415-43662002000100019\&lng=en $>$. Acesso em: 04 jan. 2016.

TEIXEIRA, A. H. C. Clima: radiação solar; temperatura do ar; umidade do ar; velocidade do vento; precipitação pluviométrica; potencial climático da região do Submédio São Francisco para o cultivo de videira. In: LEÃO, P. C. S. Cultivo da videira. Embrapa Semiárido, 2004, p. 07-10.

TEIXEIRA, A. H. C.; MOURA, M. S. B.; ANGELOTTI, F. Cultivo da Videira: Aspectos agrometeorológicos da cultura da videira. 1 - 2. ed. Embrapa Semiárido, Sistema de Produção, 2010. Disponível em: < https://sistemasdeproducao.cnptia.embrapa.br/ FontesHTML/Uva/CultivodaVideira_2ed/clima.html>. Acesso em: 04 jan. 2016.

TEIXEIRA, A. H. C.; TONIETTO, J.; PEREIRA, G. E.; ANGELOTTI, F. Delimitação da aptidão agroclimática para videira sob irrigação no Nordeste Brasileiro. 
Agriambi, Campina Grande, v. 16, n. 4, p. 399-407, 2012. Disponível em: < http:// www.scielo.br/scielo.php?script $=$ sci_arttext\&pid $=$ S1415-43662012000400010>. Acesso em: 04 ago. 2016.

TONIETTO, J.; MANDELLI, F. Uvas Americanas e Híbridas para o Processamento em Clima Temperado. Embrapa Uva e Vinho, Sistemas de Produção. $2^{\text {a }}$ Ed. ISSN 16788761, 2003. Disponível em: < https://sistemasdeproducao.cnptia.embrapa.br/ FontesHTML/Uva/UvaAmericanaHibridaClima'Temperado/clima.htm $>$. Acesso em: 04 set. 2016.

TROEH, F. R.; THOMPSON, L. M. Solos e fertilidade do solo. São Paulo: Andrei, 2007.

VIEIRA, A. C. P.; BRUCH, K. L.; FORMIGHIERI, I.; RODEGHERO, C. A Indicação Geográfica como instrumento para o desenvolvimento de uma região: caso indicação de procedência do "Vales da Uva Goethe" - SC. PIDCC, Aracaju, ano III. Edição n. 5/2014, p. 407-425, fev. 2014. Disponível em: <www.pidcc.com.br>. Acesso em: 04 ago. 2016.

Recebido em: 26/05/2017 Aceito em: 24/05/2018 